\title{
Estimation of Local Density Augmentation and Hydrogen Bonding between Pyridazine and Water under Sub- and Supercritical Conditions Using UV-Vis Spectroscopy
}

\author{
Kimitaka MinaMI,*† Tomotsugu OHaShI,** Muneyuki Suzuki,** Takafumi AIzawa,* \\ Tadafumi AdSCHIRI, $* * *$ and Kunio ARAI* \\ *Research Center for Compact Chemical Process, National Institute of Advanced Industrial Science \\ and Technology, 4-2-1, Nigatake, Miyagino, Sendai 983-8551, Japan \\ **Department of Chemical Engineering, Tohoku University, Aoba 6-6-11 Aramaki-aza, \\ Aoba, Sendai 980-8579, Japan \\ ***Institute of Multidisciplinary Research for Advanced Materials, Tohoku University, \\ 2-1-1, Katahira, Aoba, Sendai 980-8577, Japan
}

\begin{abstract}
The local density around pyridazine was evaluated by examining the UV-vis spectral shift of pyridazine in a highpressure liquid state and supercritical water from 25 to $450^{\circ} \mathrm{C}$ and from 20 to $45 \mathrm{MPa}$. Augmentation of the local density was observed from 380 to $420^{\circ} \mathrm{C}$, and showed the maximum at a lower density than the critical density of water. The degree of hydrogen bonding was estimated in consideration of the local density augmentation. The estimated degree of hydrogen bonding under subcritical conditions without any difference between the local density and the bulk density corresponded to the previously reported results with a UV-vis absorbance spectral shift of quinoline and an NMR proton chemical shift. However, the degree of hydrogen bonding near the critical point of water was larger than that in the case that the local density augmentation was not taken into account. At $380^{\circ} \mathrm{C}$ and $0.2 \mathrm{~g} \mathrm{~cm}^{-3}$ of the bulk density there are $30 \%$ as many hydrogen bonds as those under the ambient condition, and it was around 1.5-times that without considering local-density augmentation.
\end{abstract}

(Received July 7, 2006; Accepted August 24, 2006; Published November 10, 2006)

\section{Introduction}

Various chemical reactions using supercritical fluids have been investigated as a breakthrough that reduces environmental problems. Especially, water $\left(T_{\mathrm{c}}=374^{\circ} \mathrm{C}, P_{\mathrm{c}}=22.1 \mathrm{MPa}\right.$, and $\rho_{\mathrm{c}}$ $=0.323 \mathrm{~g} \mathrm{~cm}^{-3}$ ) is well known as an environmentally benign solvent, and it has been reported that the various inorganic and organic reactions, such as the synthesis of metal oxide nanoparticles, ${ }^{1-3}$ the dehydration of alcohols, ${ }^{4-6}$ the hydrolysis of ethers, ${ }^{4,5,7,8}$ Friedel-Crafts alkylation ${ }^{9}$ and the acylation ${ }^{10}$ of aromatics occur without a catalyst in supercritical water. These reactions are expected to be controlled by the temperature and pressure (or density), ${ }^{11,12}$ since drastic changes in the solvent properties, especially the polarity ${ }^{13,14}$ and hydrogen-bonding ability ${ }^{15}$ of solvents, cause changes in chemical potential of the reactants, intermediates and products, and thus the activation energy. The solvent properties, which influence the reactions, are mainly the local level around the solute. Therefore, it is necessary to understand the local solvent properties around the solute, especially near to the critical region, in which the loca density is different from the bulk. ${ }^{16-41}$ In addition, the hydrogenbonding ability of the solvent also has an influence on the reaction. ${ }^{42}$ In the case of nucleophilic reactions, because the nucleophilic species are hydrated by solvent molecules, the

$\dagger$ To whom correspondence should be addressed.

E-mail: nankim@tagen.tohoku.ac.jp reaction rate decreases along with an increase in the hydrogen bonding ability of the solvent. ${ }^{42}$ However, hydrogen bonding between the solute and solvent molecules in supercritical water has not yet been clarified.

UV-vis spectroscopy has been used to estimate the hydrogen bonding through the spectral shift of a probe molecule. ${ }^{45-48}$ The frequency of the maximum absorbance, $v_{\max }$, can be empirically represented by the Kamlet-Taft equation ${ }^{42-48}$ based on linear solvation energy relationships (LSER), as follows:

$$
v_{\max }=A+s \pi^{*}+a \alpha+b \beta,
$$

where the first term, $A$, is the frequency of the maximum absorbance under the condition with no solvent effect, such as in a gaseous state or a vacuum. The second term, $s \pi^{*}$, is for interactions between the solute and solvent polarities. The third term, $a \alpha$, and fourth term, $b \beta$, are for interactions between the hydrogen-bond acceptor ability (HBA) of the solute and the hydrogen-bond donor ability (HBD) of the solvent and the interactions between HBD of the solute and HBA of the solvent, respectively. The solvent parameters $\left(\pi^{*}, \alpha\right.$, and $\left.\beta\right)$, which are obtained from the spectral shift, have found widespread use in describing many solvation effects observed for physicochemical properties, such as rate constants and equilibrium constants based on LSER. ${ }^{42-48}$

In addition, the spectral shift under conditions without the effect of hydrogen bonding can be theoretically expressed by the physical properties of the solvent, which are the refractive 
index, $n$, and the electric constant, $\varepsilon$, based on the Onsager reaction field theory. ${ }^{49}$ The McRae-Bayliss expression ${ }^{50}$ is well known as one of these expressions, and is represented as:

$$
v_{\max }=A+B \frac{n^{2}-1}{2 n^{2}+1}+C\left(\frac{\varepsilon-1}{\varepsilon+2}-\frac{n^{2}-1}{n^{2}+2}\right),
$$

where the first term is the same as the first term of Eq. (1). The second term is for interactions between the dipole of the solute and an induced dipole of the solvent; the third term is for interactions between the dipole of the solute and the dipole of the solvent. The second and third terms are theoretical expressions of the second term of Eq. (1). ${ }^{42,44}$

In supercritical fluids, the observed frequency, $v_{\max }$, is different from that estimated by Eq. (2), assuming $\varepsilon$ is the same as the bulk $\varepsilon$. Kajimoto attributed this difference to the difference in the local $\varepsilon$ and the bulk one. ${ }^{31}$ Further, the local density around the solute has been estimated from the evaluated local $\varepsilon$ using the relation between $\varepsilon$ and density $\rho$ of the solvent. ${ }^{18-51}$ When a solute that has hydrogen bonding ability is used, these differences affect not only the difference between the local density and the bulk density, but also the hydrogen bonding in supercritical water. Osada et al. ${ }^{34}$ determined the parameters of Eq. (2) about quinoline in non-hydrogen bonding solvents under the ambient condition, and suggested a method to estimate the hydrogen-bonding ability of sub- and supercritical water. Since the bulk $\varepsilon$ was used for the calculated frequency by Eq. (2), the estimated difference in the supercritical region included the effect of not only hydrogen bonding, but also local polarity. It is necessary to divide the effect of the local polarity and the effect of hydrogen bonding.

In this work, the UV-vis spectra of pyridazine, which has HBA to shift its $n-\pi^{*}$ absorption band, ${ }^{51}$ was measured in water of various conditions (temperatures were from 25 to $450^{\circ} \mathrm{C}$ and pressures were from 20 to $45 \mathrm{MPa}$ ). The relationship between the spectral frequency of pyridazine and the density of water was estimated based on the spectral shifts under the conditions of no difference between the local density and the bulk density. Then, the local density was estimated using the frequency in the supercritical region by this relationship, and the degree of hydrogen bonding, which is the probability for the formation of hydrogen bonding relative to that for water under ambient conditions, was evaluated in consideration of the local density.

\section{Experimental}

\section{Reagents and chemicals}

Distilled and deionized water with a resistivity of $18.2 \mathrm{M} \Omega$ $\mathrm{cm}^{-1}$ was used as a solvent. The probe chosen to detect the polarity and hydrogen bonding of the solvent was pyridazine (Aldrich, 98\% purity), which does not directly relate with the reactions, but can be used as a probe solute of the solvent properties. Concerning the effect of the solvent's polarity and hydrogen bonding in the spectral shift of pyridazine under ambient condition, pentane (98\%), hexane (99\%), heptane (99\%), cyclohexane (99.5\%), diethyl ether (DEE) $(99.5 \%)$, dibutyl ether (DBE) (98\%), tetrahydrofuran (THF) $(99.5 \%)$, dimethyl formamide (DMF) (99.5\%), dimethyl sulfoxide (DMSO) (99\%), methanol (99.8\%), and ethanol (99.5\%), were supplied from Wako Pure Chemical Industries. These chemicals were used as received.

\section{Apparatus}

A flow apparatus with a high-temperature, high-pressure

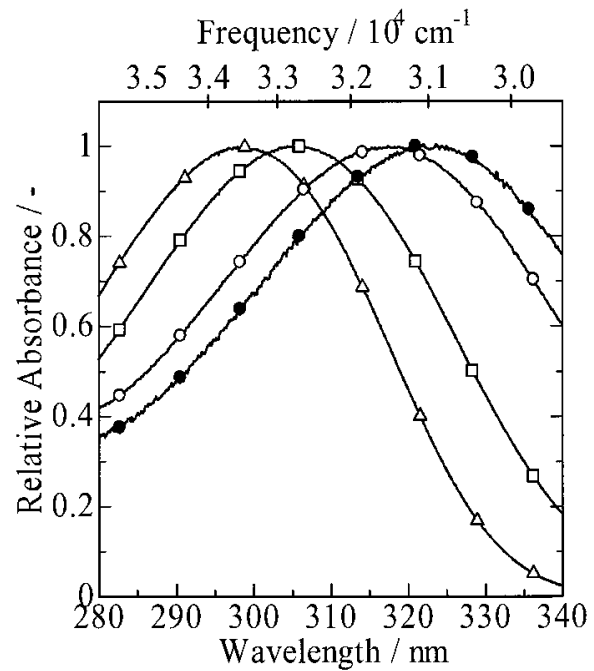

Fig. 1 UV-vis absorption spectra of pyridazine in high-temperature and high-pressure water. $\triangle-, 25^{\circ} \mathrm{C}, 35 \mathrm{MPa}\left(1.01 \mathrm{~g} \mathrm{~cm}^{-3}\right)$; - - , $200^{\circ} \mathrm{C}, 35 \mathrm{MPa}\left(0.89 \mathrm{~g} \mathrm{~cm}^{-3}\right) ;-\mathrm{O}-, 400^{\circ} \mathrm{C}, 35 \mathrm{MPa}\left(0.47 \mathrm{~g} \mathrm{~cm}^{-3}\right)$; $400^{\circ} \mathrm{C}, 26 \mathrm{MPa}\left(0.19 \mathrm{~g} \mathrm{~cm}^{-3}\right)$.

optical cell, used for in-situ UV-vis spectroscopy in supercritical water, and a general procedure were described in our previous publication..$^{40}$ Sapphire windows with a special configuration (凸 type: called "totsu" in Japanese) was used for the cell to reduce the cell dead volume. The cell internal volume was $0.25 \mathrm{~cm}^{3}$ and the path length was $3.0 \mathrm{~mm}$; the residence time in the cell was about $7 \mathrm{~s}$ at $380^{\circ} \mathrm{C}$ and $30 \mathrm{MPa}$, described in a previous publication. ${ }^{40}$ The aqueous solution of pyridazine in the cell had concentrations from $3.1 \times 10^{-3}$ to 23.4 $\times 10^{-3} \mathrm{~mol} \mathrm{~kg}^{-1}$. The pressures were from 20 to $45 \mathrm{MPa}$, and the temperatures were from 25 to $450^{\circ} \mathrm{C}$.

The spectrophotometer quartz cell on the market was used to measure the spectra in liquid solvents under ambient condition (pentane, hexane, heptane, cyclohexane, DEE, DBE, THF, DMF, DMSO, ethanol, methanol, and water), instead of the high-temperature, high-pressure cell.

\section{Results and Discussion}

\section{Dependence of spectral shift on conditions}

The $n-\pi^{*}$ absorption band of pyridazine in water from 25 to $400^{\circ} \mathrm{C}$ and at 26 and $35 \mathrm{MPa}$ are shown in Fig. 1. The maximum absorbance of all spectra in this work was from 0.1 to 0.8 and the signal/noise ratio was from 34 to 130 . As the temperature increased or the pressure decreased, the absorption band was shifted toward the longer wavelength side (red-shift). When the spectra of pyridazine were measured in supercritical water, the spectra of the recovered solution were remeasured under ambient conditions to estimate any possible decomposition. From the absorbance of the spectra of the recovered solutions, it was confirmed that the sample was scarcely decomposed under any of the given conditions, and that these spectra had the same shapes and the same maximum wavelengths as the spectra measured before the experiment. Therefore, these spectral shifts were probably not influenced by the chemical species, like the decomposition products. The maximum wavelength under different concentrations of pyridazine, at which the maximum absorbance was from 0.05 to 0.38 , was observed at almost the same position. From these 


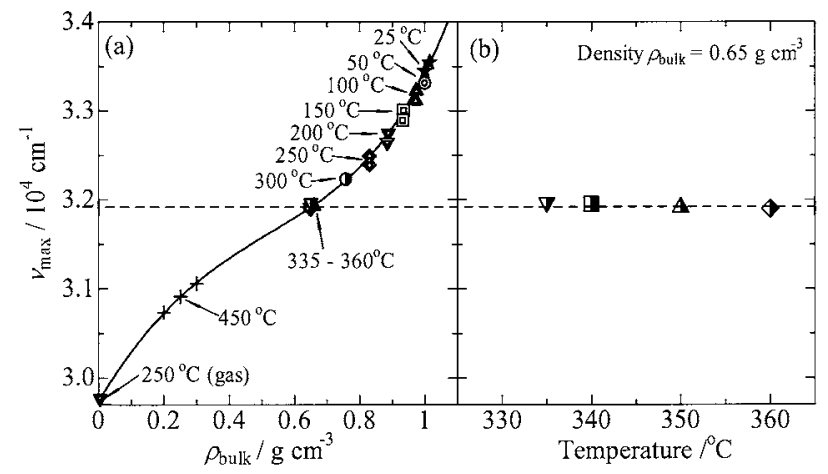

Fig. $2 v_{\max }$ of pyridaizine in water up to $450^{\circ} \mathrm{C}$ as a function of density (a) and at $0.65 \mathrm{~g} \mathrm{~cm}^{-3}$ of density as a function of temperature (b). Solid curve is the fitting result with a fourth-order polynomial (Eq. (3)).

results, we assumed that the effect on a spectral shift by the concentrations of pyridazine could be neglected under our experimental concentrations. It is reported that such a shift is caused by both a decrease of the solvent polarity and hydrogen bonding according to a decrease of the density, and by a shift of the vibration mode of the probe with temperature..$^{33,36}$

All of the spectra were fitted with a fourth-order polynomial to evaluate the frequency of the maximum absorbance. The determined frequencies were described as a function of density of the water, in liquid phase from 25 to $365^{\circ} \mathrm{C}$ at 30 and 35 $\mathrm{MPa}$, high-temperature $\left(450^{\circ} \mathrm{C}\right)$ supercritical phase, and gas phase at $250^{\circ} \mathrm{C}$ and $1 \mathrm{MPa}$, as shown in Fig. 2a. In order to separate the effects of the temperature and density on the frequency, the frequencies at a constant density of $0.65 \mathrm{~g} \mathrm{~cm}^{-3}$ were plotted against the temperature, as shown in Fig. 2b. In Fig. 2a, it is found that the frequencies increased with increasing density. On the other hand, a change of the frequency was hardly observed with a change of the temperature at constant density, as shown in Fig. 2b. Osada et al. ${ }^{34}$ also reported that the frequency of quinoline, whose molecular structure is similar to pyridazine, does not show any change with temperature (25$300^{\circ} \mathrm{C}$ ) in gaseous argon. Thus, the spectral shifts of pyridazine can be attributed mainly to the effect of the polarity of the solvent and hydrogen bonding.

\section{Estimation of the local density around pyridazine}

First, the local density of water around pyridazine in the supercritical state was estimated from the spectral shift. Although estimations of the local density are still scarce under high-temperature, high-pressure conditions, such as supercritical water, and further under conditions forming hydrogen bonds between the solute and solvent molecules, that the local density around the solute is very different from the bulk density in supercritical fluids, especially near the critical region, was observed previously. The procedure for estimating the local density was referred to in previous studies..$^{21-27,31-35}$

In this work, the equation expressing the spectral shift is determined by fitting the density of water and the experimentally observed frequencies under conditions where the local density can be regarded as the same as the bulk density. The effect of the solvent polarity on the spectral shift has been expressed by the physical properties of the solvent, which are $\varepsilon$ and $n$, as theoretical equations in previous reports. ${ }^{42,49,50}$ However, the effect of hydrogen bonding on the spectral shift has been mainly estimated as an empirical parameter. ${ }^{42-46}$

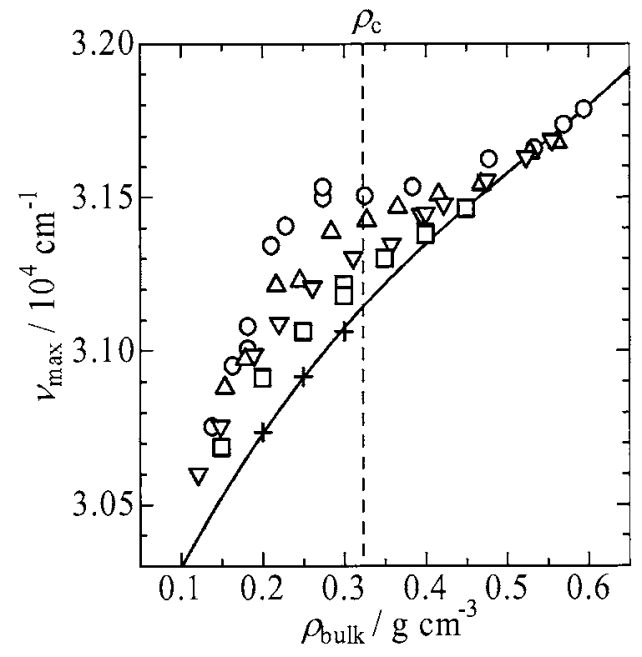

Fig. $3 v_{\max }$ for supercritical water as a function of bulk density. 0,$380 ; \triangle, 390 ; \nabla, 400 ; \square, 420 ;+, 450^{\circ} \mathrm{C}$. Solid curve is the result of Eq. (3).

Therefore, the spectral shift of pyridazine, which depends upon the effect of both the polarity and the hydrogen bonding, ${ }^{51}$ can not be theoretically expressed. The relationship of frequencies $v_{\max }$ and $\rho$ in the range from the gaseous state to the liquid state was fitted with a fourth-order polynomial by the least-squares method as follows:

$$
v_{\max }=\left(2.12 \rho^{4}+1.70 \rho^{3}-6.23 \rho^{2}+6.09 \rho+29.7\right) \times 10^{3} .
$$

In Fig. 2a, the fitted equation is shown as a smooth curve. Since the thermal movement of the solute and the solvent molecules overcomes the intermolecular force between them, the difference between the local density and the bulk density is expected to decrease by increasing the temperature, even in the supercritical state. ${ }^{28,29,35,40}$ The local density at a very high temperature $\left(450^{\circ} \mathrm{C}\right)$ was regarded as being the same as the bulk density in this work.

Then, the local density in the near-critical region is estimated from the difference between the calculated frequency from the equation and the observed frequency. The frequencies of pyridazine observed in supercritical water from 380 to $450^{\circ} \mathrm{C}$ are shown in Fig. 3. Equation (3) is also shown in this figure. The frequencies exhibited good accordance with Eq. (3) in the density above $0.5 \mathrm{~g} \mathrm{~cm}^{-3}$, but deviated upward from Eq. (3) in the range from 0.1 to $0.5 \mathrm{~g} \mathrm{~cm}^{-3}$. Further, this deviation was pronounced with approaching to the critical temperature and density. These phenomena mean that the local density around pyridazine is higher than the bulk density in the supercritical region, as described above. It has been reported that for benzophenone, ${ }^{33}$ quinoline, ${ }^{34}$ 4-nitroaniline, ${ }^{35}$ and 4 nitroanisole ${ }^{40}$ in supercritical water, the differences between the local density and the bulk density are related to the free volume and the compressibility of the solvent. Therefore, in the liquid state and in a very high-temperature $\left(450^{\circ} \mathrm{C}\right)$ supercritical state, in which the isothermal compressibility is close to zero, the local density should be almost the same as the bulk one. Obviously, $v_{\max }$ should be related to the local atmosphere; Eq. (3) can be regarded as the relationship between the frequency of pyridazine and the local density.

In this work, the local density, $\rho_{\text {local, }}$ of water around pyridazine in the near critical region was calculated from the 


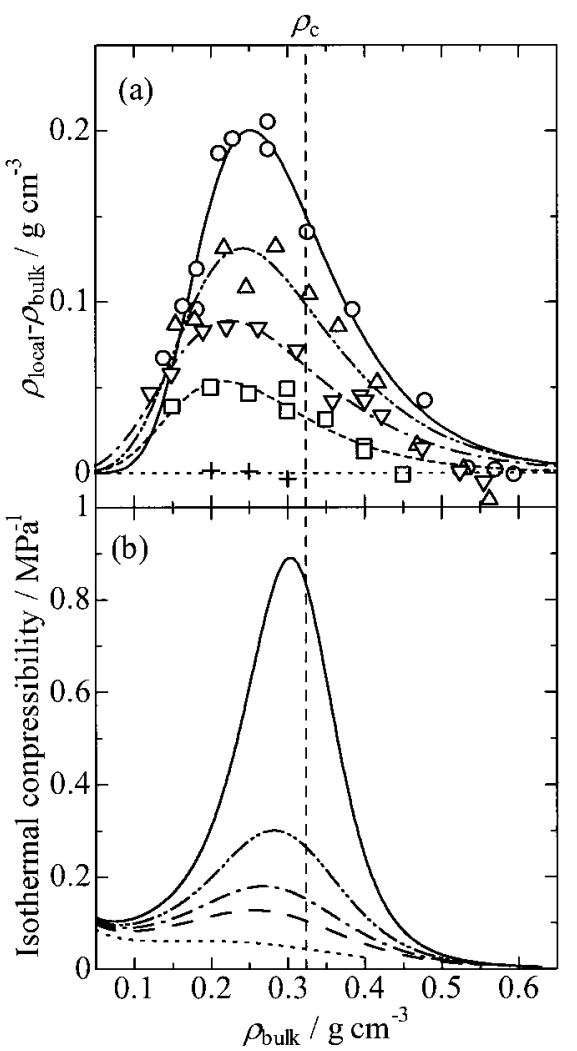

Fig. 4 Difference of local density and bulk density (a) and isothermal compressibility of supercritical water (b). $\mathrm{O},-, 380$; $\triangle,-\cdots-\cdots, 390 ; \nabla,-\cdots, 400 ; \square, \cdots \cdots, 420 ;+, \cdots \cdots \cdots \cdots \cdot, 450^{\circ} \mathrm{C}$.

measured frequency using Eq. (3). The difference between the local density and the bulk density, $\rho_{\text {local }}-\rho_{\text {bulk }}$, was defined as the excess density, $\Delta \rho$, of the local density augmentation around pyridazine. The excess density was used to be a measurement of how the local and bulk densities differed in the near critical region from 380 to $420^{\circ} \mathrm{C}$, as shown in Fig. 4a. For describing $\Delta \rho$ in supercritical fluids, the Weibull line-shape function ${ }^{23-25,38-41}$ is generally used, as follows:

$$
\begin{array}{r}
\Delta \rho=a\left(\frac{c-1}{c}\right)^{(1-c) / c}\left[\frac{\rho_{\text {bulk }}-\rho_{0}}{b}+\left(\frac{c-1}{c}\right)^{1 / c}\right]^{c-1} \times \\
\exp \left\{-\left[\frac{\rho_{\text {bulk }}-\rho_{0}}{b}+\left(\frac{c-1}{c}\right)^{1 / c}\right]^{c}+\frac{c-1}{c}\right\} .
\end{array}
$$

There is no theoretical justification for this functional form; $a$, $b, c$ and $\rho_{0}$ are fitting parameters. The $a$ is related to the maximum in excess density, and $\rho_{0}$ indicates the bulk density at $a$. The other fitting parameters $(b$ and $c$ ) are for the shape of the peak. However, Maroncelli et al. ${ }^{23-25}$ reported that it provides a good representation of the density dependence observed in most of the data sets examined. The fitting results are shown as the smooth curves in Fig. 4a. The maximum of the excess density and the bulk density in which the excess density reaches the maximum are given in Table 1 .

The difference between the local and bulk densities in supercritical fluids depends on both the solvent-solvent interactions and the solute-solvent interactions. There are the following three types of solvation under supercritical conditions according to molecular-dynamics studies. ${ }^{32}$ Because solute-solvent interactions are repulsive, the local density is
Table 1 Maximum excess density and bulk density at the maximum excess density, determined from the Weibull line

\begin{tabular}{|c|c|c|}
\hline $\begin{array}{l}\text { Temperature/ } \\
{ }^{\circ} \mathrm{C}\end{array}$ & $\begin{array}{c}\text { Maximum excess } \\
\text { density } / \mathrm{g} \mathrm{cm}^{-3}\end{array}$ & $\begin{array}{l}\text { Bulk density at maximum } \\
\text { excess density } / \mathrm{g} \mathrm{cm}^{-3}\end{array}$ \\
\hline 380 & 0.20 & 0.25 \\
\hline 390 & 0.13 & 0.24 \\
\hline 400 & 0.08 & 0.22 \\
\hline 420 & 0.05 & 0.22 \\
\hline
\end{tabular}
shape function (Fig. 4a)

lower than the bulk density. Since solute-solvent interactions are weakly attractive compared with solvent-solvent interactions, the local density augments; this behavior shows a similar behavior concerning the free volume and compressibility of the solvent because the solvent properties become predominant. Because solute-solvent interactions are much more attractive than solvent-solvent interactions, the local density augments compared with the bulk density, and the excess density is maximized at a density much lower than the critical density.

The excess density of pyridazine was compared with the isothermal compressibility of water (Fig. 4b) as follows. First, the excess density at $380^{\circ} \mathrm{C}$ is not too large, while the isothermal compressibility is large. The reason for this difference is probably that there is a limit to the local density because the volume in which the solvent can affect the spectral shift of the solute is limited. Second, the maximum of the excess density was observed at a lower value than the critical density $(0.323 \mathrm{~g}$ $\mathrm{cm}^{-3}$ ). The third is that the peak shape of the excess density became broader with increase in temperature in the range of the bulk density being lower than $0.2 \mathrm{~g} \mathrm{~cm}^{-3}$. We think this is probably due to hydrogen-bond formation between the pyridazine and water molecules.

The one or two water molecules around pyridazine are strongly attracted through hydrogen bonding..$^{52}$ In the high bulk density region $\left(0.3-0.5 \mathrm{~g} \mathrm{~cm}^{-3}\right)$, since the water molecules around pyridazine augmented by polarity interactions are much more than those attracted by hydrogen bonding, and thus its contribution is higher, the behavior of the excess density was similar to that of the isothermal compressibility of water. However, the water molecules augmented by polarity interactions decreased with a decrease of the bulk density $(0.1$ $0.3 \mathrm{~g} \mathrm{~cm}^{-3}$ ) and an increase of temperature, but it seemed that one or two water molecules were still strongly attracted to the pyridazine molecule via hydrogen bonding. Therefore, since the effect of the attracted water molecules by hydrogen bonding on the spectrum, which is the effect of not only hydrogen bonding, but also polarity interactions, became dominant at a lower bulk density of water, the maximum of the excess density exhibited a lower density than the critical density, and the shape of the excess density became broader along with an increase in temperature in the lower density region. In addition, peaks appeared even at 400 and $420^{\circ} \mathrm{C}$, where no local-density augmentation occurred around non-hydrogen bonding solutes in previous literature. ${ }^{35,40}$ These results probably mean that interactions between the solute and the solvent molecules are strong due to the hydrogen bonding.

\section{Degree of the hydrogen bonding of supercritical water}

Next, the degree of hydrogen bonding between pyridazine and water molecules was estimated based on the above discussion. The spectral shifts of pyridazine depend on both the polarity of 
a



b



Fig. 5 Experimentally obtained frequencies $v_{\max }$ at $25^{\circ} \mathrm{C}$ as a function of the polarity term, $(\varepsilon-1) /(\varepsilon+2)-\left(n^{2}-1\right) /\left(n^{2}+2\right)(\mathrm{a})$, and as a function of calculated frequency $v_{\text {max-cal }}$ by Eq. (2) (b). 1, Pentane; 2, hexane; 3, heptane; 4, cyclohexane; 5, DEE; 6, DBE; 7, THF; 8, DNF; 9, DMSO; 10, ethanol; 11, methanol; 12, water.

the solvent and hydrogen bonding. ${ }^{51}$ A procedure proposed by Osada et al. ${ }^{34}$ for dividing the effect of hydrogen bonding from the spectral shifts was employed in this study.

The parameters $(A, B, C)$ in Eq. (2) were determined to estimate the effect of the polarity interactions between pyridazine and water for the spectral shift using the spectrum shift in non-hydrogen bonding solvents (pentane, hexane, heptane, cyclohexane, DEE, DBE, THF, DMF, and DMSO). The $v_{\max }$ of pyridazine in non-polar solvents (pentane, hexane, heptane, and cyclohexane), in which the effect of the interactions between the dipole of the solute and that of the solvent can be neglected, were constant at $29744 \pm 20 \mathrm{~cm}^{-1}$. This means that the interaction between the dipole of the solute and the induced dipole of the solvent can be neglected, namely $B=0 \mathrm{~cm}^{-1}$; the frequency at no solute-solvent interaction, $A$, is $29744 \mathrm{~cm}^{-1}$. There are some reports ${ }^{31,51}$ that, since the effect of the dipole-dipole interactions is much larger than the effect between dipole-induced dipole interactions when the polarities of both solute and solvent are large, the second term of Eq. (2) can be neglected. In this work, since the polarity of both pyridazine and water were relatively large, these results are reasonable. The constant $C\left(=1417 \mathrm{~cm}^{-1}\right)$ was determined using the frequencies of pyridazine in polar solvents (DEE, DBE, THF, DMF, and DMSO), as shown in Fig. 5a. In Fig. 5b, the experimentally obtained frequencies are shown against the

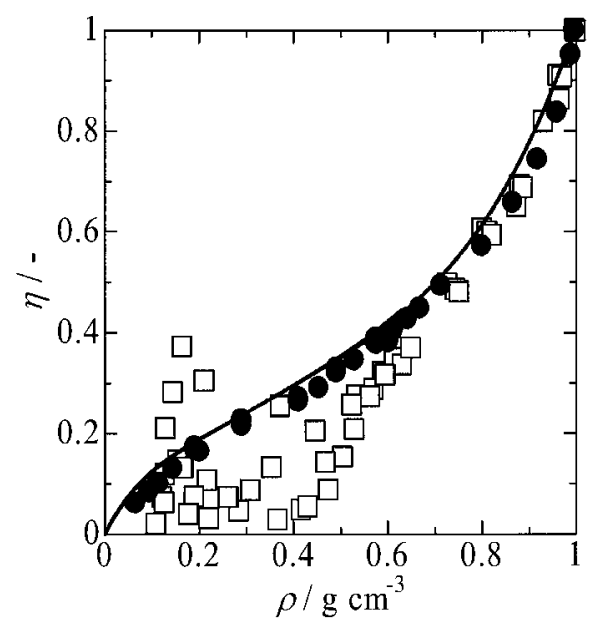

Fig. 6 Degree of hydrogen bonding $\eta$ of water as a function of water density $\rho$. - , this work; $\square$, data from Osada et al. (Ref. 44); , data from Matubayasi et al. (Ref. 15).

calculated frequencies by fitted Eq. (2).

The frequencies of pyridazine in HBD solvents (ethanol, methanol, and water) are also shown in Fig. 5b. As shown in the figure, the experimentally obtained frequencies in HBD solvents had higher values than those calculated. Osada et al..$^{34}$ attributed these differences to the effect of hydrogen bonding between the solute and the solvent. In the case that there is no difference between the local density and the bulk density, the difference between the experimentally obtained frequency and the calculated frequency from Eq. (2) is due to the effect of hydrogen bonding. More specifically, this effect can be attributed to the effect between HBA of pyridazine and HBD of water, ${ }^{51,52}$ namely, the third term $a \alpha$ of the Kamlet-Taft equation (Eq. (1)).

The difference of $v_{\max }, \Delta v$, between Eqs. (2) and (3) was estimated as the effect of hydrogen bonding. The refractive index and the electric constant in sub- and supercritical water were reported by Schiebener et al. ${ }^{53}$ and Uematsu et al. ${ }^{11}$ respectively. All of the data were normalized by the value under the ambient condition, $\Delta v_{25^{\circ} \mathrm{C}}=2591 \mathrm{~cm}^{-1}$. Thus, these normalized values of $\eta$, shown in Fig. 6, expresses the ratio of hydrogen bonding based on the ambient condition. In the same figure, the normalized literature data of the UV-vis absorbance spectral shifts of quinoline from Osada et al. ${ }^{34} \eta=$ $\Delta v_{\text {difference }} / \Delta \nu_{\text {difference25 }}{ }^{\circ}$, are shown for a comparison. The normalized literature data of the NMR proton chemical shift from Matubayasi et al. ${ }^{15} \eta=\sigma / \sigma_{25^{\circ} \mathrm{C}}$, are also shown in this figure, which is widely accepted to be an index of the hydrogen bonding of water molecules.

The results of this work under high-density conditions (0.7 - 1 $\mathrm{g} \mathrm{cm}^{-3}$ ) were in remarkably good agreement with the UV absorbance spectral shift reported by Osada. This means that the determined value $\eta$ depends mainly on the solvent conditions, rather than the solute species. However, the data from Osada deviated under the near-critical conditions (0.1 - 0.6 $\mathrm{g} \mathrm{cm}^{-3}$ ). These results are probably because the data from Osada were due to both the hydrogen bonding and the local polarity in the supercritical region. The data of the NMR from Matubayasi were in good agreement with the results of this work. Since the estimated value by NMR expresses the average of hydrogen bonding for all water molecules in the system, it can not distinguish between the local and the bulk. The results 




Fig. 7 Degree of hydrogen bonding $\eta$ of supercritical water at $380^{\circ} \mathrm{C}$ in consideration of the local density augmentation. The solid curve is $\eta$ without local density augmentation.

of this work probably express the relationship between the density of water and hydrogen bonding, regardless of the kind of solute.

The hydrogen bonding in the near-critical region was estimated in consideration of the local density. The local density, as shown in Fig. 3, was used to estimate the effect of the local polarity on the frequency from Eq. (2); the difference of the calculated frequency by Eq. (2) and the experimental observed frequency was defined as the effect of hydrogen bonding on the frequency. The defined effect of hydrogen bonding between pyridazine and water at $380^{\circ} \mathrm{C}$ was normalized by the value under the ambient condition; thus, normalized values were plotted against the bulk density as shown in Fig. 7. The hydrogen bonding under the conditions without localdensity augmentation is also shown as a curve in the same figure. As shown in Fig. 7, the hydrogen bonding between pyridazine and water in the near-critical conditions is larger than that without local density augmentation. For example, for a bulk density of $0.2 \mathrm{~g} \mathrm{~cm}^{-3}$, the hydrogen bonding was about $30 \%$ of the ambient condition, and about 1.5-times that $(\eta=$ 0.2 ) of no effect of the local density augmentation.

\section{Conclusions}

The local density around pyridazine, which is a solute used to form hydrogen bonds with water molecules, was estimated using UV-vis spectroscopy in supercritical water. The local density augmentation showed feature behavior for the solute that formed the hydrogen bonds. The excess density of the local density augmentation was reached at a bulk density lower than the critical density of water, and the shape of the excess density became broad with an increase of temperature for a bulk density lower than $0.2 \mathrm{~g} \mathrm{~cm}^{-3}$. These behaviors are probably due to the one or two water molecules around pyridazine attracted by hydrogen bonding, which is stronger than polarity interactions.

The degree of hydrogen bonding was estimated while considering the local density. The estimated values for hydrogen bonding without local density augmentation were in agreement with the data from other measurements, and the ratio of hydrogen bonding based on the ambient condition probably depends on the density of water, regardless of the kind of solute.
The degree of hydrogen bonding in a large local density augmentation region was higher than that without the local density augmentation. At a bulk density of $0.2 \mathrm{~g} \mathrm{~cm}^{-3}$, the hydrogen bonding was about $30 \%$ of that under the ambient condition, and about 1.5-times that without local density augmentation.

\section{References}

1. T. Adschiri, K. Kanazawa, and K. Arai, J. Am. Soc., 1992, $75,1019$.

2. T. Adschiri, Y. Hakuta, K. Sue, and K. Arai, J. Nanoparticle Res., 2001, 3, 227.

3. K. Sue, K. Murata, K. Kimura, and K. Arai, Green Chem., 2003, 5, 659 .

4. P. E. Savage, Chem. Rev., 1999, 99, 603.

5. D. Bröll, C. Kaul, A. Krämer, P. Krammer, T. Richter, M. Jung, H. Vogel, and P. Zehner, Angew. Chem., Int. Ed., 1999, 38, 2998.

6. N. Akiya and P. E. Savage, Ind. Eng. Chem. Res., 2001, 40, 1822.

7. J. D. Taylor, J. I. Steinfeld, and J. W. Tester, Ind. Eng. Chem. Res., 2001, 40, 67.

8. M. Sasaki, M. Furukawa, K. Minami, T. Adschiri, and K. Arai, Ind. Eng. Chem. Res., 2002, 41, 6642.

9. T. Sato, G. Sekiguchi, T. Adschiri, and K. Arai, Chem. Commun., 2001, 17, 1566.

10. J. S. Brown, R. Gläser, C. L. Liotta, and C. A. Eckert, Chem. Commun., 2000, 14, 1295.

11. N. Akiya and P. E. Savage, Chem. Rev., 2002, 102, 2725.

12. J. B. Ellington, K. M. Park, and J. F. Brennecke, Ind. Eng. Chem. Res., 1994, 33, 965.

13. M. Uematsu and E. U. Franck, J. Phys. Chem. Ref. Data, 1980, 9, 1291.

14. H. Weingärtner and E. U. Franck, Angew. Chem., Int. Ed., $\mathbf{2 0 0 5}, 44,2672$.

15. N. Matubayasi, C. Wakai, and M. Nakahara, J. Chem. Phys., 1997, 107, 9133.

16. T. Morita, K. Kusano, H. Ochiai, K. Saitow, and K. Nishikawa, J. Chem. Phys., 2000, 112, 4203.

17. K. Nishikawa and T. Morita, Chem. Phys. Lett., 2000, 316, 238.

18. S. Nugent and B. M. Ladanyi, J. Chem. Phys., 2004, 120, 874.

19. T. Umecky, M. Kanakubo, and Y. Ikushima, J. Phys. Chem. B, 2002, 106, 11114

20. M. Kanakubo, T. Umecky, C. C. Liew, T. Aizawa, K. Hatakeda, and Y. Ikushima, Fluid Phase Equilib., 2002 194, 859 .

21. J. Lu, B. Han, and H. Yan, Phys. Chem. Chem. Phys., 1999, 1,3269

22. J. Otomo and S. Koda, Chem. Phys., 1999, 242, 241.

23. R. Biswas, J. E. Lewis, and M. Maroncelli, Chem. Phys. Lett., 1999, 310, 485.

24. W. Song, R. Biswas, and M. Maroncelli, J. Phys. Chem. A, 2000, 104, 6924.

25. J. E. Lewis, R. Biswas, A. G. Robinson, and M. Maroncelli, J. Phys. Chem. B, 2001, 105, 3306.

26. T. Aizawa, Y. Ikushima, N. Saitoh, K. Arai, and R. L. Smith, Jr., Chem. Phys. Lett., 2002, 357, 168.

27. J. F. Kauffman, J. Phys. Chem. A, 2001, 105, 3433.

28. S. A. Egorov, J. Chem. Phys., 2000, 112, 7138.

29. S. A. Egorov, J. Chem. Phys., 2000, 113, 1950.

30. S. A. Egorov, A. Yethiraj, and J. L. Skinner, Chem. Phys. 
Lett., 2000, 317, 558.

31. O. Kajimoto, Chem. Rev., 1999, 99, 355.

32. S. C. Tucker, Chem. Rev., 1999, 99, 391.

33. G. E. Bennett and K. P. Johnston, J. Phys. Chem., 1994, 98 , 441.

34. M. Osada, K. Toyoshima, T. Mizutani, K. Minami, M. Watanabe, T. Adschiri, and K. Arai, J. Chem. Phys., 2003, $118,4573$.

35. H. Oka and O. Kajimoto, Phys. Chem. Chem. Phys., 2003, $5,2535$.

36. N. Kometani, K. Takamiya, Y. Yonezawa, F. Amita, and O. Kajimoto, Chem. Phys. Lett., 2004, 394, 85.

37. K. Sugimoto, H. Fujiwara, and S. Koda, J. Supercrit. Fluids, 2004, 32, 293.

38. T. Aizawa, M. Kanakubo, Y. Ikushima, R. L. Smith, Jr., T. Saitoh, and N. Sugimoto, Chem. Phys. Lett., 2004, 393, 31.

39. T. Aizawa, M. Kanakubo, Y. Hiejima, Y. Ikushima, and R. L. Smith, Jr., J. Phys. Chem. A, 2005, 109, 7353.

40. K. Minami, M. Mizuta, M. Suzuki, T. Aizawa, and K. Arai, Phys. Chem. Chem. Phys., 2006, 8, 2257.

41. K. Minami, T. Aizawa, M. Kanakubo, Y. Hiejima, H. Nanjo, and R. L. Smith, Jr., J. Supercrit. Fluids, in press.
42. C. Reichardt, "Solvents and Solvent Effects in Coorganic Chemistry", 2003, VCH, Weinheim.

43. M. J. Kamlet, J. L. Abboud, and R. W. Taft, J. Am. Chem. Soc., 1977, 99, 6027.

44. C. Laurence, P. Nicolet, and M. T. Dalati, J. Phys. Chem., 1994, 98,5807

45. R. W. Taft and M. J. Kamlet, J. Am. Chem. Soc., 1976, 98 , 2886.

46. M. J. Kamlet and R. W. Taft, J. Am. Chem. Soc., 1976, 98 , 377.

47. J. Lu, J. S. Brown, C. L. Liotta, and C. A. Eckert, Chem Commun., 2001, 7, 665

48. J. Lu, J. S. Brown, E. C. Boughner, C. L. Liotta, and C. A. Eckert, Ind. Eng. Chem. Res., 2002, 41, 2835.

49. L. Onsager, J. Am. Chem. Soc., 1936, 58, 1486.

50. E. G. McRae, J. Phys. Chem., 1957, 61, 562.

51. G. J. Brealey and M. Kasha, J. Am. Chem. Soc., 1955, 77, 4462.

52. W. Caminati, P. Moreschini, and P. G. Favero, J. Phys. Chem. A, 1998, 102, 8097.

53. P. Schiebener, J. Straub, J. M. H. L. Sengers, and J. S. Gallagher, J. Phys. Chem. Ref. Data, 1990, 19, 677. 